\title{
DEVELOPMENT OF ULTRASONIC FATIGUE FOR RAPID, HIGH TEMPERATURE FATIGUE STUDIES IN TURBINE ENGINE MATERIALS
}

\author{
A. Shyam ${ }^{1}$, C. J. Torbet ${ }^{1}$, S. K. Jha ${ }^{2}$, J. M. Larsen ${ }^{3}$, M. J. Caton ${ }^{3}$, C. J. Szczepanski ${ }^{1}$, T. M. Pollock ${ }^{1}$, J. W. Jones ${ }^{1}$ \\ ${ }^{1}$ Materials Science and Engineering, University of Michigan, Ann Arbor, MI-48109 USA \\ ${ }^{2}$ Universal Technology Corporation, Dayton, Ohio 45432 USA \\ ${ }^{3}$ Materials and Manufacturing Directorate, AFRL/MLLMN Wright Patterson AFB, Dayton, OH-45433 USA
}

Keywords: Ultrasonic Fatigue, Crack Initiation, Fatigue Micromechanisms, Laser Machining.

\begin{abstract}
A system for ultrasonic fatigue testing at temperatures as high as $700^{\circ} \mathrm{C}$ and at positive mean stresses has been developed. Its use is demonstrated by examining the fatigue behavior in the lifetime range of $10^{5}$ to $10^{9}$ cycles for the nickel-base superalloy Rene' 88 DT at 20 and $593^{\circ} \mathrm{C}$ for a load-ratio of 0.05 . Crack initiation occurred from large grains and from inclusions, consistent with crack initiation behavior at conventional test frequencies. Surface condition influenced fatigue behavior at ambient temperature, where electropolished specimens had considerably shorter lives than as-machined specimens. At $593^{\circ} \mathrm{C}$, however, no effect of surface condition on fatigue lifetime was observed since subsurface initiation occurred for both electropolished and asmachined specimens. Fatigue life, at a given stress appears to be shorter when testing at ultrasonic frequencies compared to the behavior observed at conventional frequencies and the exact causes for this remain to be determined. It is also demonstrated that fatigue cracks could be initiated and grown from micronotches with dimensions on the order of grain size.
\end{abstract}

\section{Introduction}

In recent years there has been a growing interest in accelerating the development and use of new materials in critical aerospace systems. An important part of this effort involves substantial improvement of fatigue life prediction capabilities. However, the prediction of residual fatigue life in critical turbine components is complicated by the variability in measured fatigue behavior of the complex structural alloys required for engines and airframes. This variability, commonly manifested as scatter in experimentally determined fatigue lifetimes, is often significantly greater than that for other mechanical properties such as yield strength, ductility and ultimate tensile strength. [1,2]. In general, scatter in fatigue life increases at low stress amplitudes, where crack initiation and short crack propagation control lifetime [3-5] and where long crack growth behavior is less important [6,7]. In this regime, the sensitivity to microstructural variability not only complicates life prediction, but presents a challenge for design of new alloys and microstructures for optimum resistance to fatigue failure. Here microstructure is defined broadly to include porosity, inclusions, constituent particles and non-homogeneous distributions of size and orientation of critical microstructure features, as well as the more commonly identified parameters, such as grain size, phase volume fraction and crystallographic texture. Numerous studies have been conducted in the last fifty years to identify the physical mechanisms of fatigue in structural alloys and to better understand how microstructure affects mean fatigue properties. Of particular interest are the processes that control fatigue crack initiation and early growth and several excellent reviews can be found in the literature [8-12].

Traditional approaches to life prediction treat fatigue life variability as a statistical problem where fatigue life data are acquired, distribution functions for the observed lifetimes are identified and probabilities of survival for given operating conditions and desired lifetimes are subsequently assigned. Most fatigue life data are assumed to follow standard statistical distributions [13-18]. In some cases statistical treatments allow the differentiation of key microstructural parameters, such as grain size, pore size and inclusion size that are presumed to control crack initiation or short crack propagation behavior $[13,14,17,18]$. However, this approach is limited, among other factors, by the difficulty of coupling microstructure variability and fatigue life variability.

Because of the complexity of fatigue crack initiation processes and the increased need to predict fatigue lives well beyond the practical measurement range, probabilistic approaches have been examined with growing interest. Probabilistic approaches extend beyond statistical approaches in that micromechanisms for crack initiation and/or early crack propagation are identified by experiment or assumed and incorporated into probabilistic life prediction models. The variability in microstructural parameters is then determined experimentally or approximated by Monte Carlo or more advanced computational methods.

While significant progress has been made, the modeling of fatigue behavior and, in particular, the development of accurate analytical approaches to total lifetime prediction have not achieved the level of sophistication that is enjoyed in modeling deformation and fracture behavior. A central challenge is the stochastic nature of fatigue where so-called "single events", dependent on microstructural variability, can determine lifetime. Furthermore, it has been experimentally difficult to examine in a statistically significant manner, fatigue behavior at low to intermediate stresses where long fatigue lives are observed. Ultrasonic fatigue is a promising tool to interrogate some of the issues mentioned above.

\section{Ultrasonic Fatigue}

The ultrasonic fatigue technique offers an attractive approach to study the crack initiation and early crack propagation behavior because cyclic frequencies can be as much as three orders of magnitude greater than conventional testing. This enables acquisition of significant data over a wide range of accumulated cycles and lifetimes that is simply not possible to achieve with testing at conventional frequencies. In ultrasonic fatigue a sound wave is injected into the specimen under appropriate conditions to cause the specimen to vibrate in mechanical resonance. The strain 
imposed on the gage section can be monitored and controlled by adjusting the amplitude of the input signal. With this approach, a specimen is tested in mechanical resonance at frequencies of approximately $20 \mathrm{kHz}$. The advantages of this in terms of the ability to accelerate tests are obvious. For example, at $20 \mathrm{kHz}$, applying $10^{8}$ cycles requires approximately 3 hours and applying $10^{9}$ cycles can be completed typically within 1 day. Therefore, a significant amount of data can be established in a very short period of time in the intermediate fatigue life regime. Thus, the fatigue behavior at cycles more representative of the expected service life can be determined experimentally, rather than estimated from extrapolations.

The technique was first explored in the 1950s and the early work through 1980 was reviewed by Willertz in 1980 [19]. More recently, Mayer has offered a comprehensive review of improvements in the past ten years, especially regarding the use of ultrasonic fatigue for fatigue crack growth threshold studies [20]. In the United States, early work was begun by Tien and coworkers in the late 1970s and early 1980s [21,22] but in recent years, research effort has been concentrated primarily in Japan and Europe, where the technique is enjoying considerable use there as a tool for very long fatigue life prediction $[23,24]$. The growing interest in ultrasonic fatigue is driven in part by the increased need to predict lifetimes in aging structures and is made possible by dramatic improvements in the accuracy of control instrumentation for ultrasonic fatigue.

Numerous studies have been conducted showing that the fatigue behavior of many important structural materials systems, including aluminum, titanium and nickel based alloys can be determined effectively by ultrasonic fatigue methods [19,20,23]. Importantly, frequency effects may not be significant for many structural materials unless environmental attack is occurring simultaneously. The objective of the work described in this paper is to examine the potential use of ultrasonic fatigue in the study of the relationship between microstructural variability and fatigue life in structural turbine alloys, especially at long fatigue lives. We describe an ultrasonic fatigue test system capable of operation at temperatures as high as $600^{\circ} \mathrm{C}$ under variable mean stress loading. Initial results of high temperature ultrasonic fatigue studies are presented for the disk alloy Rene' 88 DT [25].

\section{Experimental Procedure}

The ultrasonic fatigue test system that has been developed for fatigue studies on superalloys and other high temperature materials is shown in Figure 1. A high accuracy ultrasonic amplifier drives the piezoelectric transducer. Feedback from an inductive vibration gage is used to control vibration amplitude and frequency to within $1 \%$. Cycles can be applied in pulses as short as $25 \mathrm{~ms}$ (500 cycles) to prevent specimen heating during cycling at room temperature. Specimens with diameters of 5-6 $\mathrm{mm}$ and overall dimensions similar to specimens used in conventional fatigue testing are typically used. Other specimen shapes, such as hourglass specimens are also used. The transducer is isolated from the mean load by a specially constructed cage and the transducer, load train and specimen are designed such that the specimen is in resonance at or near $20 \mathrm{kHz}$, with displacement anti-nodes occurring at the specimen ends. The mean load is applied at a flange which is located at an exact displacement node and therefore, does not affect the ultrasonic load train. Specimen heating is accomplished by induction heating and Figure 2 shows the induction coil arrangement around a standard cylindrical ultrasonic fatigue specimen of Rene' 88 DT. The temperature at the center of the specimen is measured and controlled with a noncontact infra-red pyrometer. The induction coil design is optimized to provide uniform heating along the entire length of the gage section. Induction heating in this manner produces a temperature variation of $\pm 3^{\circ} \mathrm{C}$ in the gage section of the cylindrical specimen.

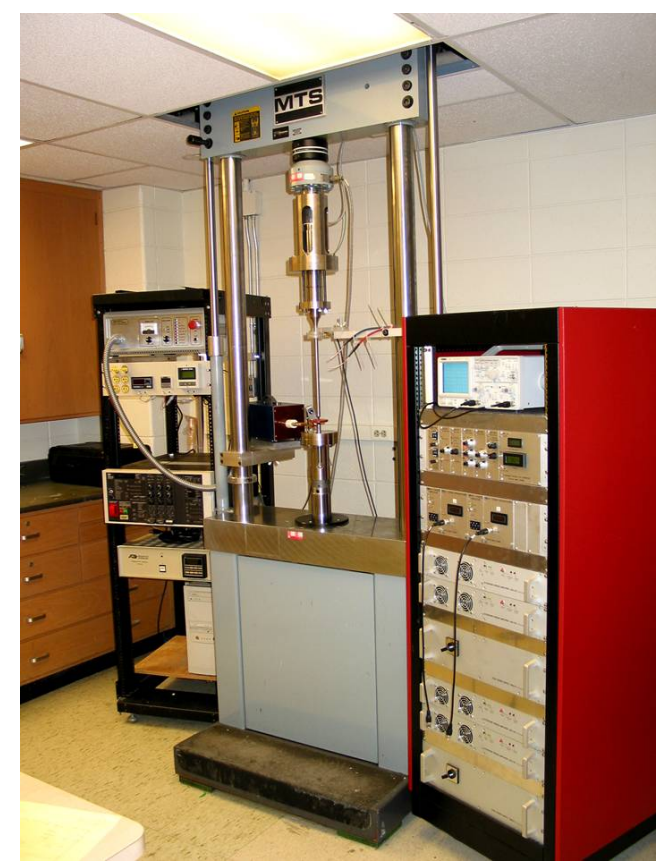

(a)

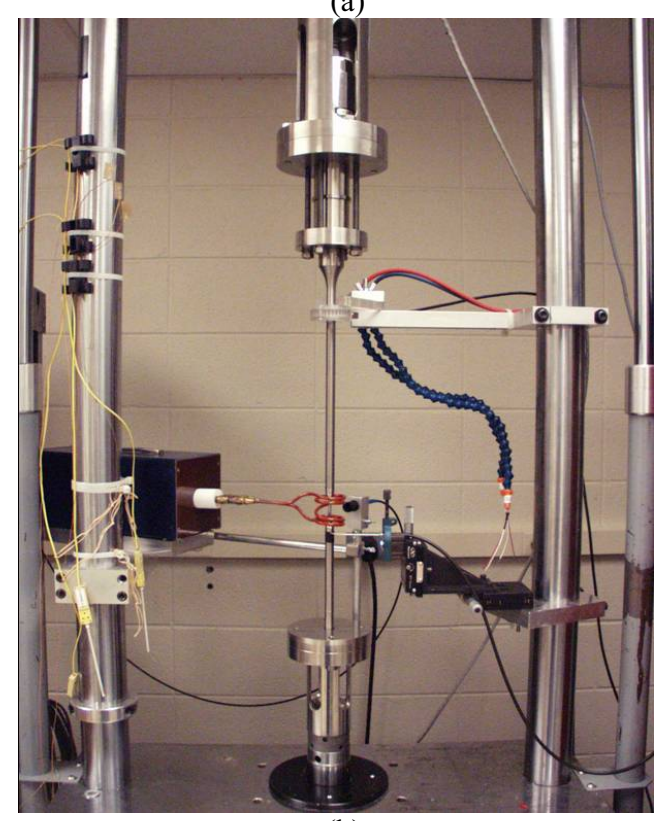

(b)

Figure 1: The ultrasonic fatigue testing system capable of testing with superimposed mean stresses at elevated temperature (a) the entire system with the controls and (b) the ultrasonic fatigue load train.

Fatigue tests were conducted at a load-ratio of 0.05 and temperatures of $20^{\circ} \mathrm{C}$ and $593^{\circ} \mathrm{C}$. The desired mean stress was 
applied using a servohydraulic fatigue testing system and the alternating stress was accomplished with ultrasonic loading. Fatigue cycles were applied in pulses of $500 \mathrm{~ms}$ followed by a pause of $900 \mathrm{~ms}$ at $20^{\circ} \mathrm{C}$. This was done to prevent the specimen from heating as a result of high frequency cycling. At $593^{\circ} \mathrm{C}$, however, ultrasonic loading was continuous since the heat generated was compensated by the temperature control system. There was no statistically significant influence of pulsed loading at elevated temperature since both pulsed and continuously loaded specimens yielded similar lifetimes under a given condition.

Closed loop control of specimen displacement is achieved during fatigue. This is accomplished by measuring the displacement amplitude of the load train at the specimen using an inductance transducer. This feedback signal is then used to control specimen strain. The feedback signal is calibrated to specimen strains using the output of strain gages attached to the gage section. A high temperature strain gage was used to measure the response of the system as it is heated from 20 to $593^{\circ} \mathrm{C}$ under displacement control. It was found the strain in the specimen center increased by approximately $6 \%$ as a result of heating to $593^{\circ} \mathrm{C}$. This factor of 1.06 (which was verified by modeling temperature effects on resonance) was used to calibrate for imposed strains at $593^{\circ} \mathrm{C}$ by making strain measurements at room temperature.

At higher test stresses, the strain gaging technique requires extrapolation of the feedback signal/specimen strain data, rather than interpolation. Consequently, the instrument is now equipped with a high resolution, non contacting fiber optic displacement gage, also shown in Figure 2. In this figure, this probe is measuring in a lateral mode although longitudinal mode measurements are also possible. This optical probe system provides a means to continuously measure displacement at antinodal points in the specimen without disrupting the mechanical conditions required for resonance. An example of the linear relationship between the displacement at the specimen end and gage section strain, as measured by strain gages, is shown in Figure 3. Importantly, the optical gage can be used without interruption at all displacement amplitudes, and is not affected by electrical noise resulting from induction heating.

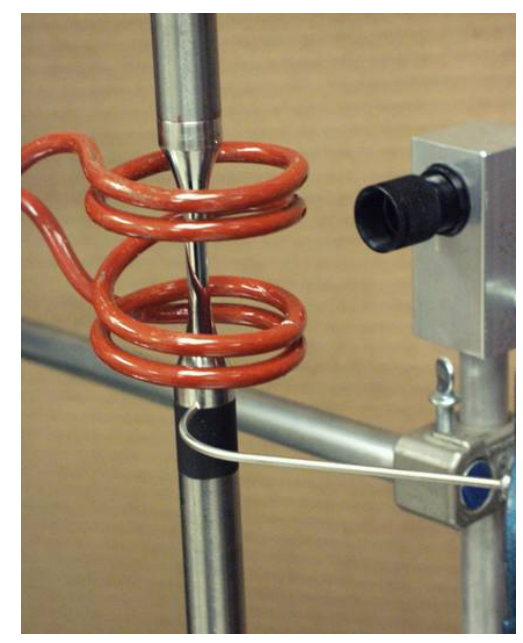

Figure 2: A Rene' 88 DT specimen with the induction heating setup. Also shown here is the non contacting fiber optic displacement gage.

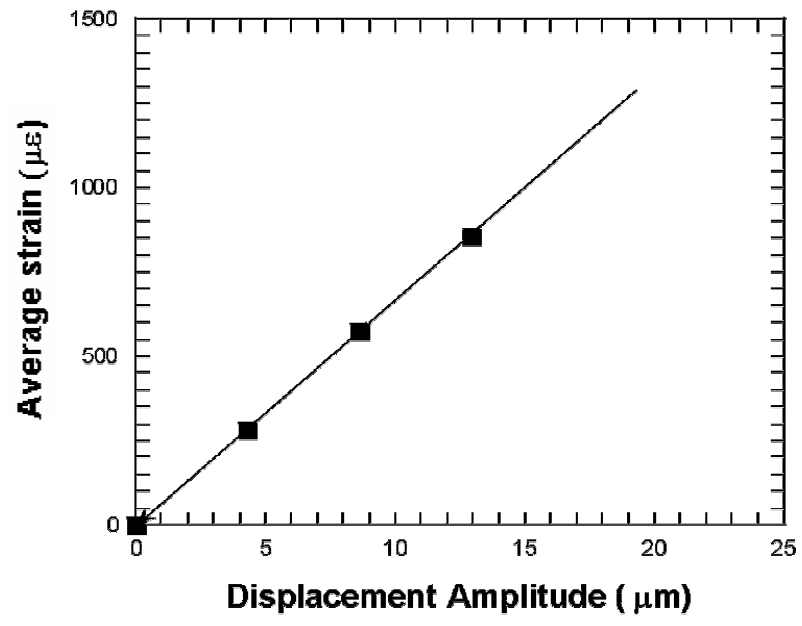

Figure 3: An experimentally generated linear calibration of average strain at the center of the gage section with the displacement amplitude at the end surfaces of the ultrasonic fatigue specimen. $\mu \varepsilon$ represents microstrains.

Specimen dimensions were fixed using an analytical solution for resonance, as described in the next section. The gage section of the fatigue specimen was $16 \mathrm{~mm}$ long and had a diameter of 5 $\mathrm{mm}$ and overall dimensions are shown in Figure 4(a). The material for this investigation came from the circumferential orientation of a pancake shape forging. The forging had received a supersolvus heat treatment prior to aging. In order to conserve material for the fatigue tests, the ends of the specimen were made of Inconel 718 and were inertia welded to the Rene' 88 DT gage section. Electropolishing was used to remove approximately 0.1 $\mathrm{mm}$ from the diameter of the gage section. This was done to eliminate surface compressive residual stresses arising from the low stress grinding process [26]. Electropolishing was conducted using an electrolyte of $55 \%$ ethanol with $35 \%$ butyl cellusolve and $10 \%$ perchloric acid at $40 \mathrm{~V}$ and $-30^{\circ} \mathrm{C}$.

The microstructure of Rene' 88 DT was examined by optical microscopy and the grain-size distribution was determined using standard linear intercept methods. The fatigue fracture surfaces were studied using scanning electron microscopy (SEM). The distance of the crack initiation site from the surface was measured in all cases where a sub-surface crack initiation event occurred.

Micronotches were machined on some fatigue specimens with the use of femtosecond pulsed lasers. The specimens were mounted on a stage on an optics worktable. A Ti:sapphire femtosecond laser system was used to produce 1000 laser pulses per second at a wavelength of $780 \mathrm{~nm}$, with each pulse $120 \mathrm{fs}$ in duration. The laser pulses were directed through a shutter which opened for $100 \mathrm{~ms}$ (100 pulses) on to a $50 \mathrm{~mm}$ focal length planoconvex lens and focused onto the specimen surface. The shutter opening time was used to control the depth of the notch. Notches of depth $<30 \mu \mathrm{m}$ and width $10 \mu \mathrm{m}$ could be made using this procedure. Details of the laser notching procedure and its effects in aluminum alloys and nickel-base superalloys could be found elsewhere [27,28]. An important feature of the femtosecond laser micromachining approach is the elimination of any melting or 
heat affected zones typically encountered with conventional laser drilling techniques [28].

\section{Modeling of Ultrasonic Fatigue}

A simple model for a fatigue specimen vibrating at a resonant frequency of $f_{\text {res }}$ consists of two blocks of mass ' $m$ ' joined by a spring with a spring constant ' $k$ '. In a dumbbell shaped specimen, the grip section approximates the mass and the weightless gage section represents the 'spring'. The resonant frequency is then

$$
f_{r e s}=\frac{1}{2 \pi} \sqrt{\frac{k}{m}}
$$

which gives the expected result of low mass objects having a higher resonant frequency. The angular frequency is given by the relationship $\omega=2 \pi \mathrm{f}_{\text {res }}$. Equation (1), although approximate can give useful insights to specimen design.

A much better representation of the displacement and strain distribution of the fatigue specimen vibrating in resonance can be achieved by solving the displacement equation for the propagation of planar tension-compression waves in a resonant part [20]. A dynamic force balance (neglecting damping effects) in the longitudinal direction which allows for changing cross-sectional area yields the following equation

$$
u^{\prime \prime}+\left(A^{\prime} / A\right) u^{\prime}+\omega^{2}(\rho / E) u=0
$$

where, $\mathrm{u}=\mathrm{u}(\mathrm{x}, \mathrm{t})$ is the displacement in the longitudinal ( $\mathrm{x})$ direction, $A$ is the cross-sectional area and $A^{\prime}$ is its gradient, $\rho$ is the density and $\mathrm{E}$ is the elastic modulus in the longitudinal direction. It is to be noted that time has been factored out in this equation and the partial derivative of the displacement would give the instantaneous strain in the x-direction. In the absence of area gradients, the analytical solution of equation (2) would indicate a sinusoidal variation [20]. If elastic modulus gradients exist in the specimen (for example, as a result of heating the specimen) a general force balance yields the following displacement equation

$$
u^{\prime \prime}+\left[\left(A^{\prime} / A\right)+\left(E^{\prime} / E\right)\right] u^{\prime}+\omega^{2}(\rho / E) u=0
$$

where $E^{\prime}$ represents a modulus gradient. The strain and displacement distributions in fatigue specimens were obtained by solving Equation (2) for the room temperature case and by solving Equation (3) for elevated temperatures. The solutions were obtained numerically by executing a fourth order Runge Kutta Nystrom (RKN) method within a Java ${ }^{\mathrm{TM}}$ computer program. The boundary conditions were implemented in the following fashion: starting at the center of the gage section which is a displacement node (with maximum known strain); the appropriate displacement equation was iteratively evaluated until the specimen ends which are displacement anti-nodes (with zero strain) are reached. The known temperature variation of the modulus of the superalloy and an experimentally measured temperature profile across the specimen was embedded within the code. Since the strain solutions are symmetric (and the displacement solutions are antisymmetric), only one half of the displacement/strain distribution in the specimen was determined in the above manner.
By solving equation (3), the displacement and strain distribution in the resonating fatigue specimen can be determined as a function of temperature and stress. An example is shown in Figure 4. Figure 4(a) is a schematic figure showing the superalloy specimen dimensions. Figure 4(b) shows model predictions of displacement and strain distribution for this half-specimen with an alternating resonant stress of $361 \mathrm{MPa}$ (for $\mathrm{R}=0.05$, this represents a maximum stress of $760 \mathrm{MPa}$ ) at the gage center. Results are presented for 20 and $593^{\circ} \mathrm{C}$, which are the temperatures of interest in this investigation. Modulus differences at the two temperatures account for the different strains at the center of the specimen. The calculations in Figure 4(b) assume resonant frequencies of $19.6 \mathrm{kHz}$ and $19.2 \mathrm{kHz}$ at 20 and $593^{\circ} \mathrm{C}$, respectively which are close to the observed resonance frequencies. The lower resonance frequency at the higher temperature arises from the increased compliance of the system. Since the displacement and strain distributions are now known as a function of temperature, we can use this information to relate the displacement amplitude at the ends of the specimen to the strain (and therefore stress) amplitude at the center of the specimen.

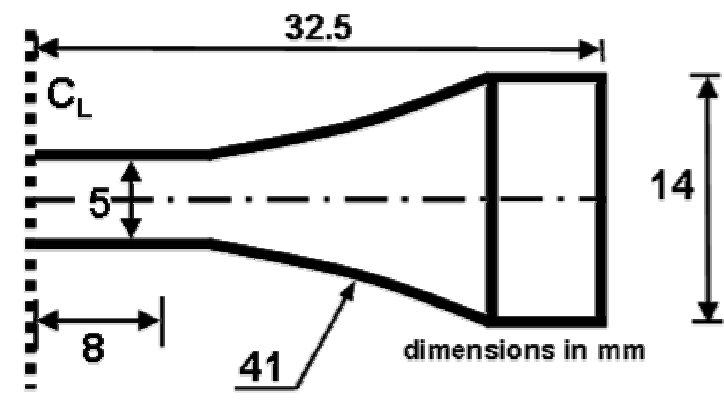

(a)

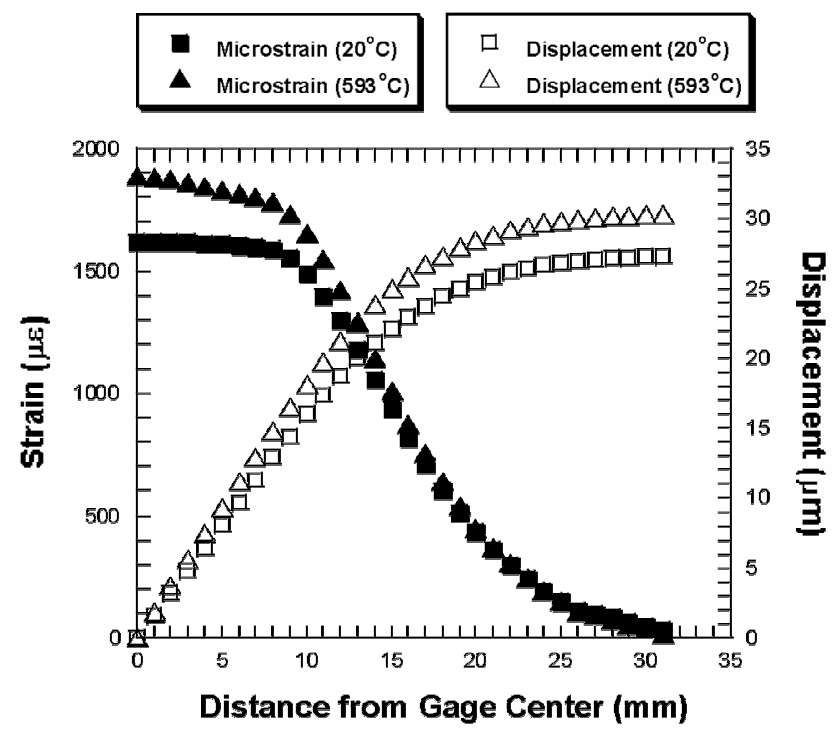

(b)

Figure 4: (a) A schematic of half of the ultrasonic fatigue specimen dimensions with a resonant frequency of $19.6 \mathrm{kHz}$ at $20^{\circ} \mathrm{C}$. All dimensions are in $\mathrm{mm}$. (b) Model prediction for strain and displacement distribution across this ultrasonic fatigue specimen. The alternating stress at the center is $361 \mathrm{MPa}$ for both temperatures. 


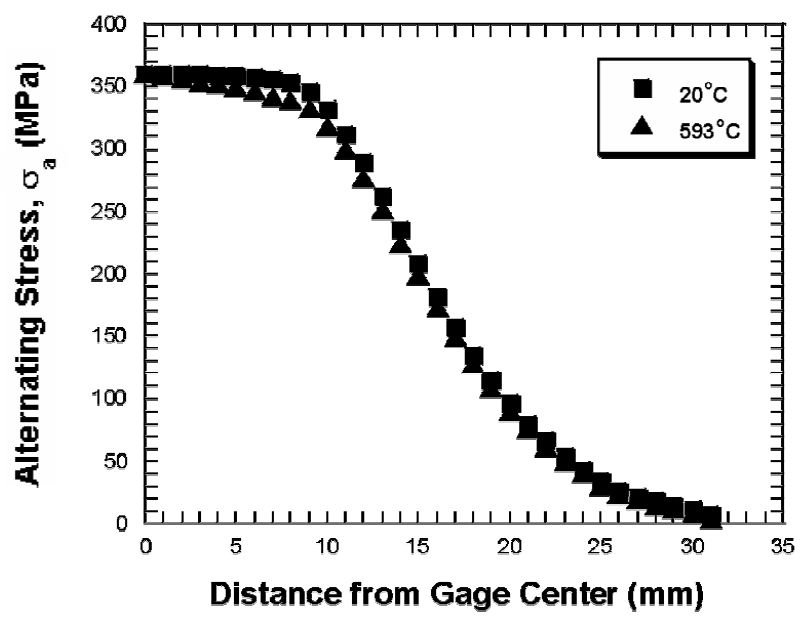

Figure 5: Comparative distribution of stresses in the specimen at the two temperatures.

Figure 5 shows the resulting stress distribution for the strain distribution shown in Figure 4(b). It can be seen that while the stresses vary by less than $2 \%$ within the gage section at room temperature, this variation is less than $5 \%$ at $593^{\circ} \mathrm{C}$. This difference is due to the changing modulus to density ratio between 20 and $593{ }^{\circ} \mathrm{C}$ as would be predicted by either equation (2) or (3). Although these stress gradients are reasonable, further improvements could be achieved by refining specimen design.

\section{Results}

\section{Microstructural Characterization}

An optical micrograph showing the microstructure of Rene' 88 DT is shown in Figure 6. This micrograph is representative of the grain structure variation associated with the circumferential orientation in the forging. Annealing twins are prevalent in the microstructure. The supersolvus heat treatment leads to a relatively coarse and equiaxed distribution of grains. In order to determine the grain size distribution, 500 grains were measured using the intercept method and the results of this procedure are summarized in Figure 7. The grain-size distribution is log-normal with a long tail and an average size close to $18.3 \mu \mathrm{m}$. The results indicate that there is a finite probability of finding grains with as much as five times the average grain size.

\section{$\underline{\text { Stress-life response at ultrasonic frequencies }}$}

The S-N behavior of Rene' 88 DT at an ultrasonic frequency and a load-ratio of 0.05 at 20 and $593^{\circ} \mathrm{C}$ has been plotted in Figure 8 . The resonant frequency of specimens was close to $19.6 \mathrm{kHz}$ at room temperature and due to increased compliance of the system at elevated temperature, the frequency decreased by approximately $300 \mathrm{~Hz}$ at $593^{\circ} \mathrm{C}$. Both low stress ground (asmachined) and electropolished specimens were used to generate the results shown in Figure 8. Fatigue lifetimes decreased at $593^{\circ} \mathrm{C}$ compared to $20^{\circ} \mathrm{C}$. Although failures were observed only at $850 \mathrm{MPa}$ at ambient temperatures, at elevated temperature, the variability in fatigue life increased as stress level was decreased.

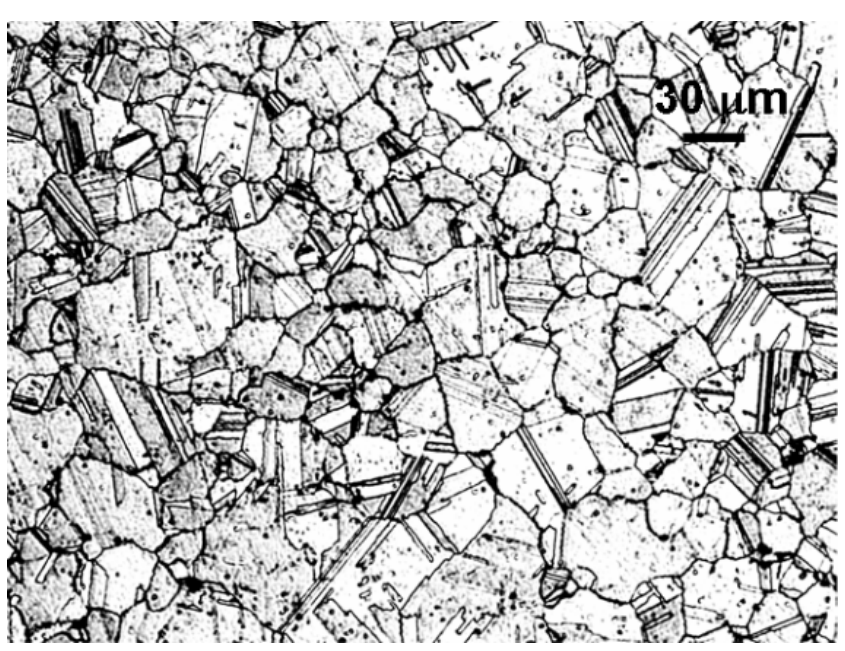

Figure 6: Optical micrograph of Rene' 88 DT.

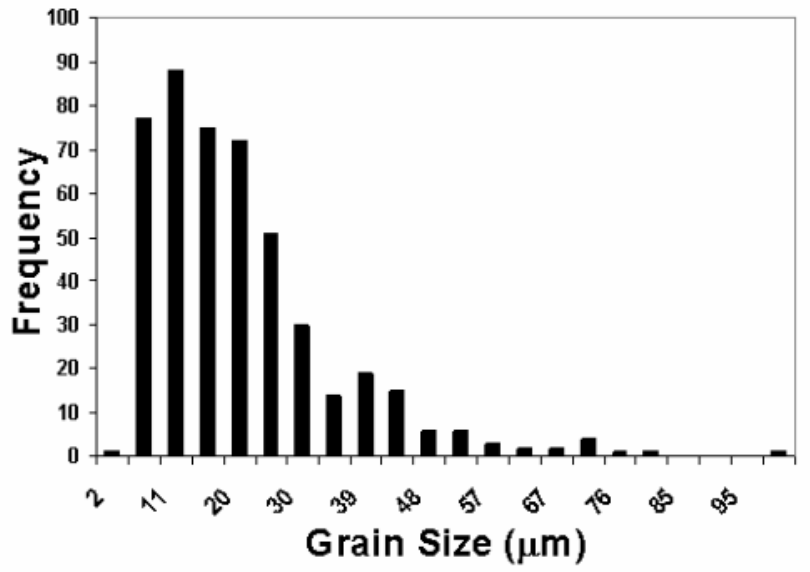

Figure 7: Lognormal distribution of grain size in Rene' 88 DT.

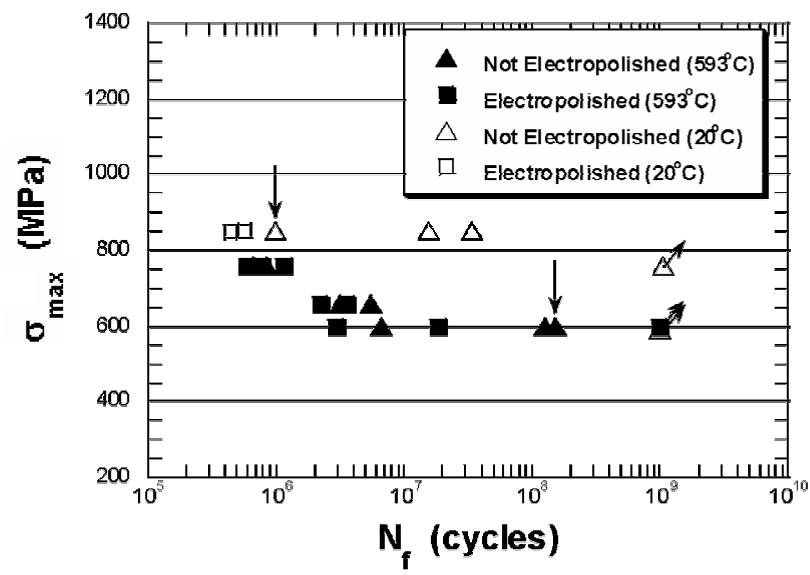

Figure 8: The stress life response of Rene' 88 DT at ultrasonic frequencies and a load-ratio of 0.05 . The data-points with downward pointing arrows are specimens with laser machined micronotches. 
At $593^{\circ} \mathrm{C}$, the variability in lifetimes was within an order of magnitude at 760 and $660 \mathrm{MPa}$ but increased to almost three orders of magnitude at $600 \mathrm{MPa}$. On two samples, laser machined micronotches were used to initiate fatigue cracks and these data points are indicated with downward pointing arrows in Figure 8.

\section{Fractography}

Fractographic examinations were conducted on all specimens that failed under ultrasonic loading conditions. All cracks initiated at sub-surface locations at $593^{\circ} \mathrm{C}$. An example of subsurface initiation is shown in the SEM image of Figure 9. Two different types of crack initiation were observed: crystallographic initiation at large grains (Figure 10(a)) and crack initiation at inclusions (Figure 10(b)). Crystallographic crack initiation was more commonly observed and a large grain (such as the one shown in Figure 10(a)) could be identified with most of these sites. In the few cases where the crack initiated from an inclusion, a larger than average grain could once again be identified in the neighborhood of the inclusion. Regardless of the nature of the crack initiation, the cracks propagated in a transgranular manner producing a rough fracture surface with the roughness decreasing as the crack size increased. This transition from relatively rough to a smoother surface can be seen in Figure 9. At crack lengths just below the transition to the fast fracture region, some striations could also be seen on the fracture surface. Evidence of striation formation is indicated by arrows in the SEM micrograph in Figure 11 .

Figure 12(a) shows the fractographic features associated with a crack that initiated from a laser micronotch in as-machined specimen with a maximum stress of $850 \mathrm{MPa}$ at room temperature. Details of the notch are shown in Figure 12(b) and, as anticipated, there are no indications of a damaged area around the notch. The shape of this notch on the fracture surface is a half-cone and its maximum width is approximately $10 \mu \mathrm{m}$ with a depth of about $25 \mu \mathrm{m}$. Fractographic observations suggest that the cracks that initiate from these notches quickly assume a semicircular shape like cracks that naturally initiate from surface flaws. Similar behavior has been observed in other studies of crack initiation and growth from laser micronotches [27].

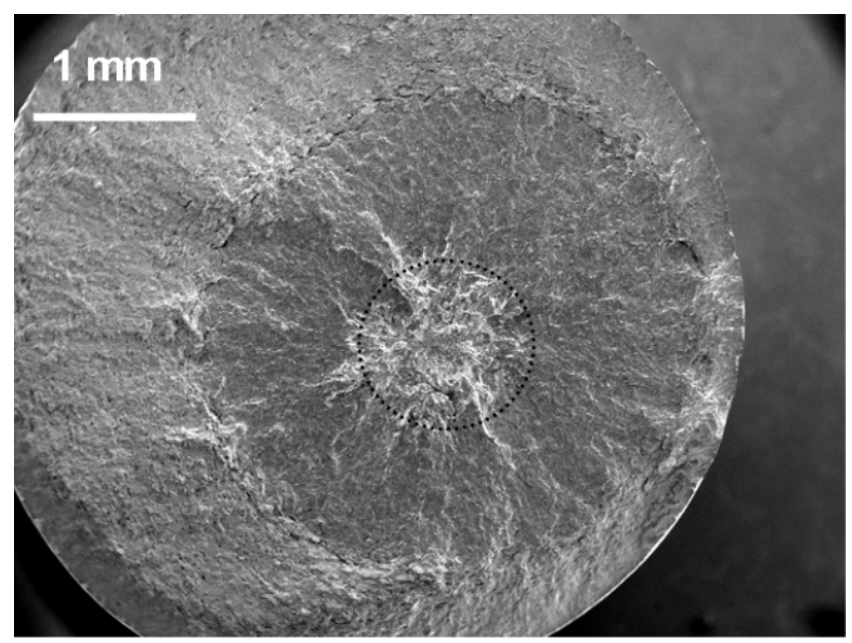

Figure 9: A subsurface crack initiation site for $850 \mathrm{MPa}$ maximum stress at $20^{\circ} \mathrm{C}$.

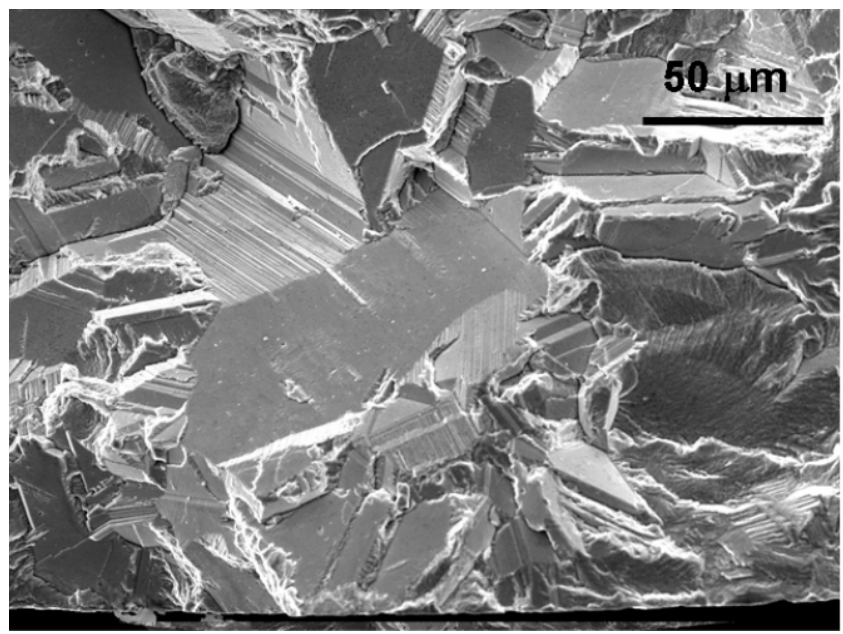

(a)

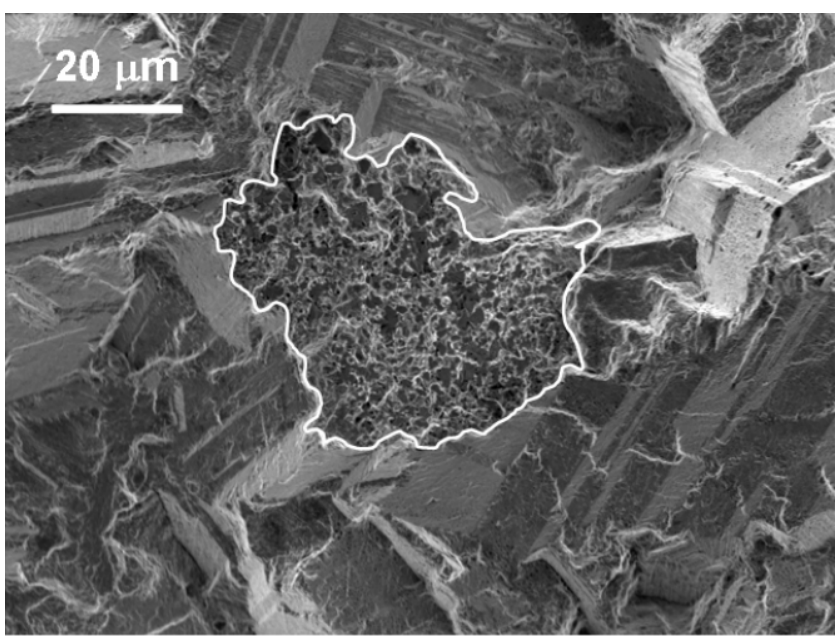

(b)

Figure 10(a) A crystallographic crack initiation site, $593^{\circ} \mathrm{C}$ with maximum stress of $760 \mathrm{MPa}$ (b) a crack initiating from an inclusion, $20^{\circ} \mathrm{C}$ with maximum stress of $850 \mathrm{MPa}$.

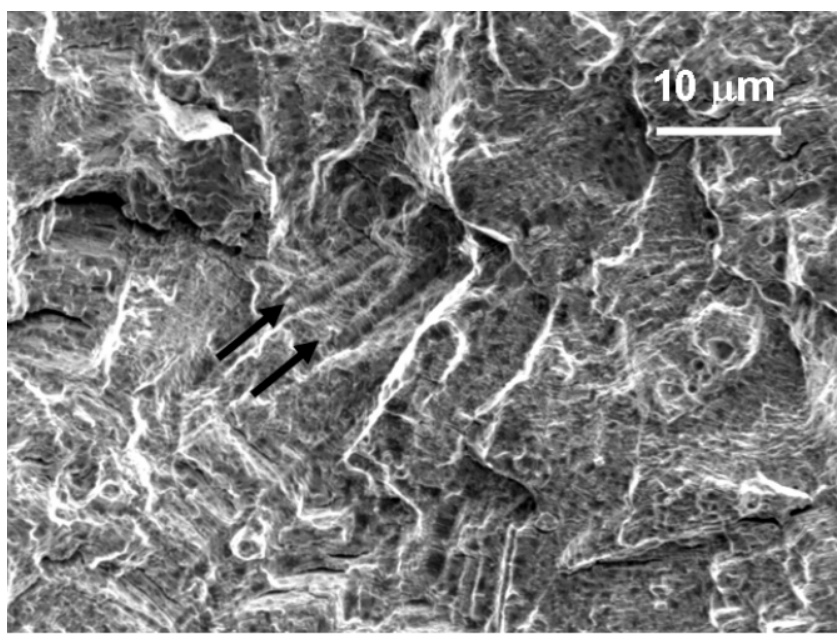

Figure 11: Micrograph indicating the presence of fatigue striations just prior to the fast fracture regime. 


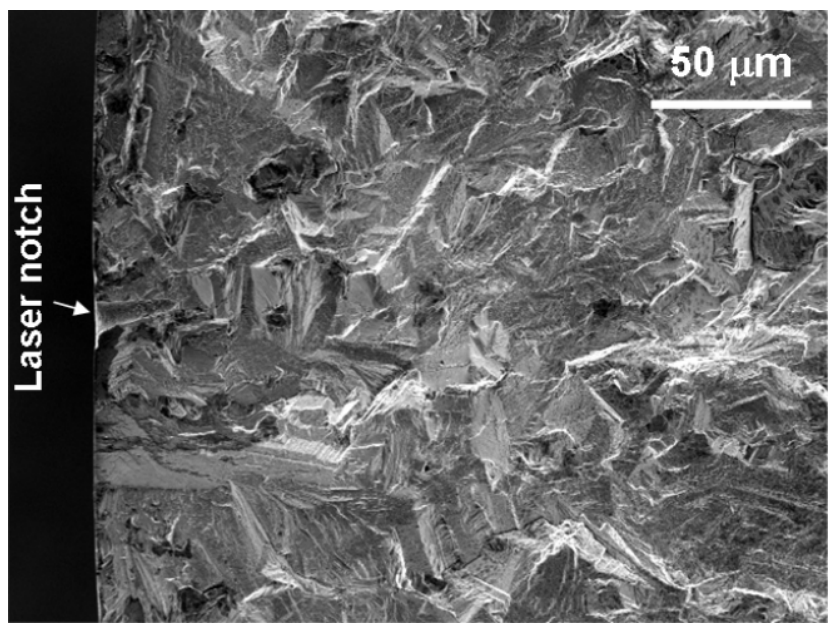

(a)

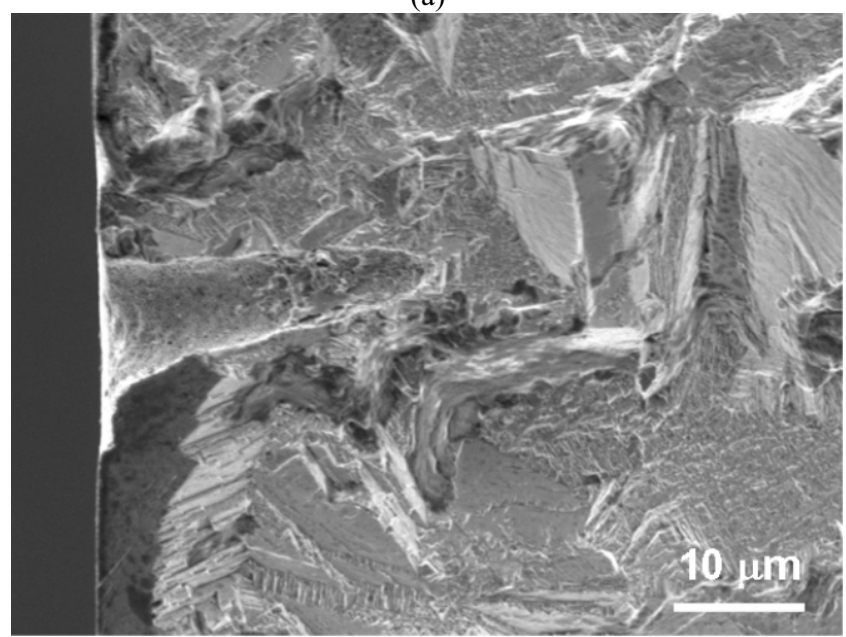

(b)

Figure 12(a) Features of crack initiated from a laser micronotch and (b) higher magnification image of the notch.

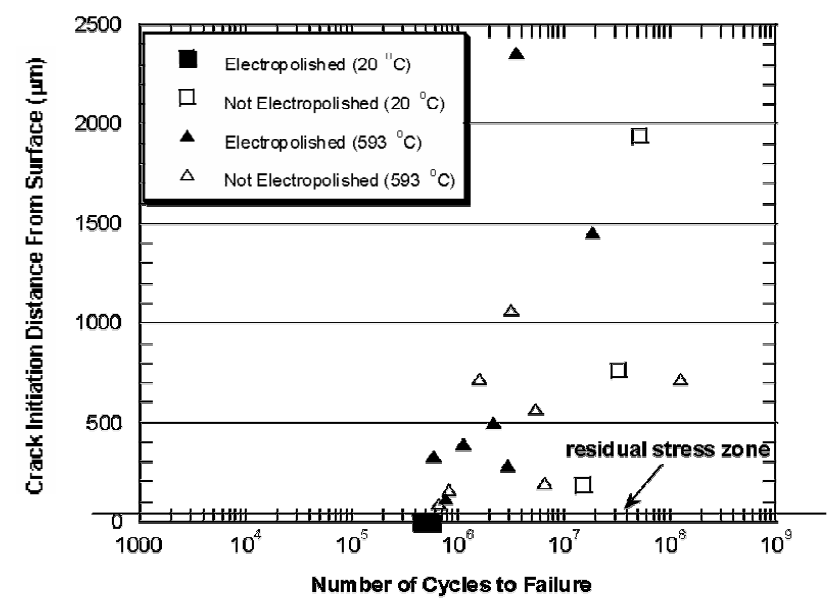

Figure 13: Effect of electropolishing on sub-surface crack initiation. The horizontal line at an initiation distance of $50 \mu \mathrm{m}$ indicates the boundary of the zone containing compressive residual stresses from machining.

\section{Discussion}

We have demonstrated the applicability of ultrasonic fatigue to test turbine disk superalloys at positive mean-stresses and elevated temperatures $\left(<600^{\circ} \mathrm{C}\right)$. With adjustments in the load train and specimen design, we can test at temperatures higher than $600^{\circ} \mathrm{C}$. Fatigue is a property of concern for many turbine engine components [29]. Of particular relevance for disk materials is quantification of any possible reduction in fatigue life due to small processing defects or particular features of the microstructure [30]. Ultrasonic testing provides opportunities for probing failures from such small defects that may be activated at very long lifetimes under nominally elastic fatigue conditions. In this section, we examine these opportunities in light of our preliminary results.

\section{Sample Surface Conditions}

As shown in Figure 8, surface condition influences the fatigue life at room temperature but not at elevated temperature. This is further illustrated in Figure 13, where the fatigue crack initiation locations are plotted against fatigue life. At room temperature, electropolished samples have a lifetime two orders of magnitude less than as-machined specimens. This behavior is consistent with the existence of surface residual compressive stresses from machining. Recent work [26] has determined that compressive residual stresses as high as $450 \mathrm{MPa}$ can exist within the asmachined layer of this superalloy. The inhibition of crack initiation by residual stress is consistent with surface crack initiation in electropolished specimens and only subsurface initiation for as-machined specimens. On the other hand, as shown in Figure 13, only sub-surface initiation occurs at elevated temperature and there is no discernible effect of surface condition on lifetime. It is possible that surface oxide formation may play a role in retarding crack initiation by limiting surface slip [31]. It is more likely that at elevated temperature, greater homogenization of deformation [32] throughout the gage volume results in smaller surface slip offset and therefore favors an interior crack initiationsite with a large grain and/or inclusion while surface/near-surface modes remain dormant. Clearly, the role of surface condition is important and more work is required for a definitive explanation of these results.

\section{Micromechanisms of Crack Initiation and Growth}

The results indicate that large grains in the size-range defined by the far right tail of the grain-size distribution shown in Figure 7 play a dominant role in crack initiation. This indicates that fatigue damage accumulation occurs more readily in the weaker regions of the microstructure, in this case large favorably oriented grains. In some cases inclusions in the neighborhood of large grains are crack initiation sites.

Crack propagation is initially crystallographic along with attendant rougher fracture surfaces but when the plastic zone size becomes larger than the average grain size and multiple slip systems can be activated, this leads to a smoother fracture surface [33]. Transitions in crack growth mechanisms have been related to both the monotonic [34] and reversed [34-36] plastic zone sizes for several disk superalloys. The monotonic plastic zone $\left(\mathrm{r}_{\mathrm{pzs}}\right)$ size is given by [37] 


$$
\mathrm{r}_{\mathrm{pzs}} \approx \frac{1}{6 \pi}\left(\frac{K_{\mathrm{max}}}{\sigma_{y s}}\right)^{2}
$$

where, $\mathrm{K}_{\max }$ represents the maximum stress intensity in the fatigue cycle and $\sigma_{y s}$ is the monotonic yield stress. Assuming an approximate stress intensity solution for an embedded elliptical crack in a flat plate [38], and using yield stress values from Huron [39] equation (4) can be used to predict the boundary for the transition from a crystallographic growth mode to a nominally mode I growth mode. In Figure 9, the crack size at which the calculated maximum plastic zone size is equivalent to the average grain-size is shown. As can be seen, this correlates well with the observed transition in crack growth mode.

The total life of any component consists of the crack initiation life, the small crack propagation life and the long crack propagation life. Taylor and Knott [40] among others have argued that a transition from small to long crack growth mechanisms occurs when the size of the crack is approximately 10 times the size of the characteristic microstructural dimension such as the grain size. If this is true, microstructural fracture mechanics operates when the crack is less than $200 \mu \mathrm{m}$ in length in this superalloy. The laser micronotching studies, in this context, provide a unique opportunity for studying the interaction of small cracks with the underlying microstructure. The notches are loaded at an ultrasonic frequency and therefore growth rates smaller than at the conventionally defined fatigue threshold $\left(10^{-10}\right.$ $\mathrm{m} /$ cycle) can also be recorded using this technique. Extension of our current experimental capabilities to probe cracks at small length scales comparable to microstructural dimensions and growing at average rates smaller than one lattice spacing per cycle is currently in progress.

\section{Comparison with stress-life data at conventional frequency}

A key issue in ultrasonic fatigue is whether fatigue behavior is dependent on frequency, especially when elevated temperature fatigue is studied. In Figure 14, we compare fatigue lifetime derived from ultrasonic fatigue tests with lifetimes resulting from a frequency of 10 and $20 \mathrm{~Hz}$ for specimens machined from the same forging [26]. All of the data generated at lower frequency was on electropolished specimens in load-control using a standard servohydraulic test system. For comparative purposes, we have reproduced the ultrasonic frequency fatigue data from electropolished specimens only at room temperature and all the data at elevated temperature (since there is no effect of surface finish condition at $593^{\circ} \mathrm{C}$ ). It can be seen that the fatigue strength at $593^{\circ} \mathrm{C}$ is significantly lower in the ultrasonic tests. The elevated temperature $\mathrm{S}-\mathrm{N}$ curve at ultrasonic frequency has shifted down by 250-300 MPa when compared to the low frequency S-N curve. It is important to note the differences in the two techniques. The ultrasonic technique is nominally elastic, so direct comparison to a stress-controlled test at low frequency under conditions where there are significant cyclic plastic strains is not straightforward [26]. Although limited amount of comparable data was generated at room temperature, Figure 14 suggests that the fatigue lives are similar at an ultrasonic frequency and $10 \mathrm{~Hz}$ under ambient conditions with a slight increase in fatigue life at $19.6 \mathrm{kHz}$. A small increase in fatigue life for the superalloy Inconel 718 at ultrasonic frequency under ambient conditions has been reported earlier by Chen et al. [41]. The crack initiation sites, however, are the same at both the frequencies. Ultrasonic fatigue techniques can therefore, be used as a tool to quickly identify the weakest links in the microstructure.

Beyond the likely differences in the overall plastic strain distribution in these two types of specimens, some of the variation in fatigue lives with temperature and frequency may be associated with thermally activated deformation mechanisms. These mechanisms could be different in the vicinity of the crack initiation sites. At room temperature, deformation is strain-rate insensitive and this manifests as little or no effect of loading frequency on fatigue lives or crack growth rates. As temperature is increased from 20 to $593^{\circ} \mathrm{C}$ (at $10 \mathrm{~Hz}$ ) or when frequency is decreased from $19.6 \mathrm{kHz}$ to $10 \mathrm{~Hz}$ (at $593^{\circ} \mathrm{C}$ ), the fatigue lives increase. It is known that increasing temperature (at the same strain rate) and strain rate (at the same temperature) have opposite effects on thermally activated deformation [42]. It is also known that for several superalloys, fatigue cracks grow at faster rates as temperature is increased and/or frequency is decreased [32]. The above discussion, therefore, indicates that any decrease in fatigue lives at ultrasonic frequencies (at $593^{\circ} \mathrm{C}$ ) may be due to favorable crack initiation conditions resulting from high frequency deformation. The favorable condition at high frequency could be higher values of slip offset (or more heterogeneously distributed slip) which makes it easier to initiate a fatigue crack [43]. Atomic force microscopy studies of slip offsets to investigate this hypothesis are currently in progress.

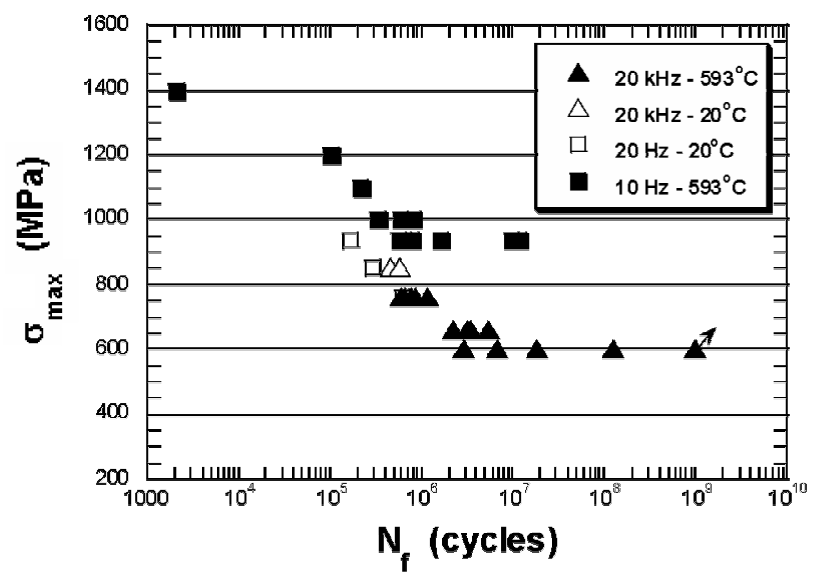

Figure 14: Comparison of the S-N response of Rene' 88 DT between conventional $(10 \mathrm{~Hz})$ and ultrasonic $(20 \mathrm{kHz})$ frequencies.

\section{Conclusions}

- An ultrasonic fatigue test system has been developed that is capable of superposed mean stresses and elevated temperatures up to $700^{\circ} \mathrm{C}$.

- The fatigue behavior of Rene' 88 DT has been examined at ultrasonic frequencies in lifetimes ranging from $10^{5}$ to $10^{9}$ for a load-ratio of 0.05 at 20 and $593^{\circ} \mathrm{C}$.

- $\quad$ Fatigue lifetime is dependent on surface condition at ambient temperature but not at elevated temperature, where all crack initiation sites were sub-surface. 
- All the crack initiation sites were associated with larger grains or at inclusions near large grains.

- It was demonstrated that micronotches produced by femtosecond pulsed laser machining could be used effectively to study crack initiation and propagation from defects whose sizes are comparable to characteristic microstructural dimensions.

- These results indicate the potential for using fatigue as a tool for examining the role microstructural variability on fatigue life.

\section{Acknowledgements}

This work was supported by AFOSR under Grant F4620-03-10069, Dr. Craig Hartley, Program Manager. The authors acknowledge the support of Mr. David Maxwell in coordinating the production of fatigue specimens.

\section{References}

1. J. Schijve, "Fatigue predictions and scatter", Fatigue Fract. Engng. Mater. Struct., 17 (1994) 381-396.

2. R.E. Little, E.H. Jebe, Statistical Design of Fatigue Experiments, Wiley, 1975.

3. S. Suresh, Fatigue of Materials, $2^{\text {nd }}$ Ed., Cambridge University Press, 1998.

4. K.S. Ravichandran, R.O. Ritchie, Y. Murakami, Eds., Small Fatigue Cracks: Mechanics, Mechanisms and Applications, Elsevier, 1999.

5. K. J. Miller, E.R. de los Rios, eds, The Behavior of Short Fatigue Cracks, EGF Pub, 1987, 461-478.

6. J. Schijve, P. De Rijk, "The fatigue crack propagation in 2024T3 alclad sheet materials from seven different manufacturers", Nat. Aerospace Lab., NRL, Amsterdam, TR M.2162, 1966.

7. D.A. Virlker, B. M. Hillberry, P.K. Goel, "The statistical nature of fatigue crack propagation”, J. Engng Mat. Tech., 1011 (1979) 148-153.

8. C. Laird, "Fatigue", in Physical Metallurgy, R.W. Cahn and P. Haasen, Eds, Elsevier, 1986, 2294-2397.

9. D.L. Davidson, J. Lankford, "Fatigue crack growth in metals and alloys: mechanisms and micromechanics", Int. Mater. Rev., 37 (1992) 45-76.

10. W Schutz, P. Heuler, "A review of fatigue life prediction models for the crack initiation and propagation phases", in Advances in Fatigue Science and Technology, Kluwer Academic Publishers, 1989, 177-219.

11. L. Lawson, E.Y. Chen, M. Meshii, "Near threshold fatigue: a review", Int. J. Fatigue, 21 (1999) S15-S34.

12. J.W. Porvan, Z. H. Zhai, "A review of fatigue crack initiation", in Time-Dependent Fracture: Proceedings of the $11^{\text {th }}$
Canadian Fracture Conference, Martinus Nijhoff Publishers, 1985.

13. M. Goto, Statistical investigations of the behaviour of microcracks in carbon steels", Fatigue Fract. Engng Mater. Struct., 14 (1991) 833-845.

14. M. Goto, Y. Yanagawa, H. Nisitani, "Statistical property in the initiation and propagation of microcracks of a heat-treated 0.45\% steel", JSME Int. 22 (1990) 235-242.

15. H. Nisitani, M. Goto, "A small crack growth law and its application to the evaluation of fatigue life", in The Behavior of Short Fatigue Cracks, K. J. Miller and E.R. de los Rios, eds, EGF Pub, 1987, 461-478.

16. M. Goto, "Statistical investigation of the behavior of small cracks and fatigue life in carbon steels with different ferrite grain sizes”, Fatigue Fract. Engng Mater. Struct. 17 (1994) 635-649.

17. Q.C. Wang, D. Apelian, D.A. Lados, "Fatigue behavior of A356-T6 aluminum cast alloys. Part I: Effect of casting defects", J. Light Metals, 1 (2001) 73-84.

18. Q.C. Wang, D. Apelian, D.A. Lados, "Fatigue behavior of A356-T6 aluminum cast alloys. Part II: Effect of microstructural constituents, J. Light Metals, 1 (2001) 85-97.

19. L.E. Willertz, "Ultrasonic fatigue", Int. Met. Rev., 25 (1980) 65-78.

20. H. Mayer, "Fatigue crack growth and threshold measurements at very high frequencies", Int. Mat. Rev., 44 (1999) 1-36.

21. J.K. Tien, "High-Power, Ultrasonic Fatigue Testing Machine", Rev. Sci. Instrum., 46 (1975) 840-846.

22. J.M. Wells, O. Buck, L.D. Roth and J.K. Tien, eds., Ultrasonic Fatigue, Proceedings, TMS/AIME, 1982.

23. S. Stanzl-Tschegg, H. Mayer, Eds., Proceedings of the International Conference on Fatigue in the Very High Cycle Regime, Institute of Meteorology and Physics, Vienna, 2001.

24. S. Stanzl-Tschegg, "Ultrasonic Fatigue", in Fatigue '96: Sixth International Fatigue Congress, Elsevier Science Inc., 1996, 1887-1898.

25. D.D. Krueger, R.D. Kissinger, R.G. Menzies, "Development and introduction of a damage tolerant high temperature nickelbase disk alloy, Rene' 88 DT", in Superalloys 1992, S.D. Antolovich et al., eds., TMS-AIME, 1992, 277-286.

26. M.J. Caton, S.K. Jha, A.H. Rosenberger, J.M. Larsen, "Divergence of Mechanisms and its effect on variability in Fatigue life of Rene' 88 DT”, Superalloys 2004.

27. A. Shyam, Y.N. Picard, J.W. Jones, J.E. Allison, S.M. Yalisove, "Small fatigue crack propagation from micronotches in the cast aluminum alloy W319", Scripta Mater., 50 (2004) 11091114 . 
28. Q. Feng, Y.N. Picard, H. Liu, S.M. Yalisove, G. Mourou, T.M. Pollock, "Femtosecond laser micromachining of singlecrystal superalloys", Superalloys 2004.

29. B.A. Cowles, "High cycle fatigue in aircraft gas turbines - an industry perspective", Int. J. Fract., 80 (1996) 147-163.

30. E.S. Huron, P.G. Roth, "The influence of inclusions on low cycle fatigue life in a P/M nickel-base disk superalloy", in Superalloys 1996, R.D. Kissinger et al., eds., TMS-AIME, 1996, 359-367.

31. J. E. King, "Role of oxides in fatigue crack propagation", Mater. Sci. Technol., 6 (1990) 19-31.

32. J. E. King, "Fatigue crack propagation in nickel-base superalloys - effects of microstructure, load ratio, and temperature", Mater. Sci. Technol., 3 (1987) 750-764.

33. A. Shyam, W.W. Milligan, "Effects of deformation behavior on fatigue fracture surface morphology in a nickel-base superalloy", Acta Mater., 52 (2004) 1503-1513.

34. P.A.S. Reed, W.F. Gale, J.E. King, "Intrinsic threshold in polycrystalline Udimet 720”, Mater. Sci. Technol., 9 (1993) 281287.

35. J.E. King, "Effects of grain size and microstructure on threshold value and near-threshold crack growth in powderformed Ni-base superalloy" Met. Sci. 16 (1982) 345-355.

36. J. Luo, P. Bowen, "Small and long fatigue crack growth behaviour of a PM Ni-based superalloy, Udimet 720", Int. J. Fatigue, 26 (2004) 113-124.

37. T.L. Anderson, Fracture Mechanics - Fundamentals and Applications, $2^{\text {nd }}$ Edition, CRC Press, 1994, 72-75.

38. Y. Murakami, Ed. in chief, Stress Intensity Factors Handbook, Vol. 2, Pergamon, 1987, 712-713.

39. E.S. Huron, "Serrated yielding in a nickel-base superalloy", in Superalloys 1992, S.D. Antolovich et al., eds., TMS-AIME, 1992, 675-684.

40. D. Taylor, J.F. Knott, "Fatigue crack propagation behaviour of small cracks; the effect of microstructure", Fatigue Fract. Eng. Mater. Struct., 4 (1981) 147-155.

41. Q. Chen, N. Kawagoishi, K. Othubo, E. Kondo, M. Sakai, T. Kizaki "Ultrasonic fatigue strength in Inconel 718", in Fifth International Symposium on Superalloys 718, 625, 706 and Various Derivatives, E.A. Loria, ed., TMS-AIME, 2001, 573-582.

42. G. E. Dieter, Mechanical Metallurgy, SI Metric Edition, McGraw-Hill, 1988, 275-324.

43. J.C. Williams, E.A. Starke Jr., "Progress in structural materials for aerospace systems", Acta Mater., 51 (2003) 57755799 . 